\title{
THE CONTRIBUTORS
}

Leslie C. Aiello is Professor of Biological Anthropology and Head of the Department of Anthropology at University College London. She is also co-editor of the Journal of Human Evolution. Born in 1946, she was educated at the University of California, Los Angeles (BA 1967; MA 1970) and the University of London (PhD 1981). Her research interests centre on the evolution of human adaptation. Research into postcranial anatomy of the fossil hominins led to the publication (with M. C. Dean) of $A n$ Introduction to Human Evolutionary Anatomy (1990) and to an ongoing major research project (with B. A. Wood, George Washington University, USA) into postcranial evolution and diversity in Plio-Pleistocene hominins. Her broader interests in the general field of human palaeobiology, and specifically in the relationship between dietary change and brain evolution and in the evolution of language and cognition, have led to a number of publications including an edited volume (with N. Jablonski) on The Origin and Diversification of Language (1998).

Alan Barnard is Reader in Social Anthropology at the University of Edinburgh. Since the early 1970s he has conducted extensive research among hunter-gatherers and former hunter-gatherers in Botswana and Namibia. He is author of Research Practices in the Study of Kinship (with Anthony Good, 1984), A Nharo Wordlist with Notes on Grammar (1985), Hunters and Herders of Southern Africa: A Comparative Ethnography of the Khoisan Peoples (1992), Kalahari Bushmen (a children's book, 1993) and many articles. He is also co-editor of the Encyclopedia of Social and Cultural Anthropology (with Jonathan Spencer, 1996).

Philip G. Chase received a Doctorate in Anthropology from the University of Arizona in 1983 and has been at the University of Pennsylvania Museum of Archaeology and Anthropology since 1987. He has studied the Middle Paeleolithic and the transition from Middle to Upper Paeleolithic from two perspectives, as a zooarchaeologist and as a researcher into the archaeological evidence for the evolution of symbolism and of human 
intelligence. He has analyzed the faunal collections from Combe Grenal and La Quina and from his own excavations at Cagny-lÉpinette and Fontéchevade.

Robin Dunbar studied Psychology and Philosophy at Oxford University before undertaking a PhD in Psychology at Bristol University. He is now Professor of Evolutionary Ecology in the School of Biological Sciences, University of Liverpool, where he leads a large research group studying the behavioural ecology and evolutionary psychology of human and non-human primates. He was previously Professor of Anthropology at University College London and Professor of Psychology at Liverpool University.

James R. Hurford is Professor of Linguistics at Edinburgh University. He has a broad interest in reconciling various traditions in linguistics which have tended to conflict. In particular, he has worked on articulating a framework in which formal representation of grammars in individual minds interacts with statistical properties of language as used in communities. The framework emphasizes the interaction of evolution, learning and communication. He is perhaps best known for his computer simulations of various aspects of the evolution of language.

Catherine A. Key is currently a lecturer in the Department of Anthropology at University College London. She teaches courses on Human Evolution and the Evolution of Cognition, reflecting her research interests in the evolution of cognition and behaviour. Prior to this she was a research assistant in the same department, using comparative analyses of human and non-human primates to investigate postcranial adaptations in the early hominids. She is currently completing her $\mathrm{PhD}$ thesis on Cooperation, Paternal Care and the Evolution of Hominid Social Structure.

Chris Knight received an MPhil degree in Russian literature from the University of Sussex in 1977 and a Doctorate in Anthropology from the University of London in 1987. He is now Reader in Anthropology at the University of East London. In addition to many journal articles on human origins, he is author of Blood Relations: Menstruation and the Origins of Culture (1991) and co-editor (with Jim Hurford and Michael Studdert-Kennedy) of Approaches to the Evolution of Language: Social and Cognitive Bases (1998).

Geoffrey F. Miller earned a BA in Biological Psychology from Columbia University, New York, in 1987, and a PhD in Cognitive Psychology from Stanford University, California, in 1993. He moved to England with an 
NSF-NATO post-doctoral research fellowship, working at the University of Sussex. He worked as a research scientist at the Max Planck Institute for Psychological Research in Munich, and is now a senior research fellow at University College London. He has published about thirty-five academic papers and presented over fifty conference talks and colloquia, ranging across the areas of visual perception, cognition, learning, robotics, neural networks, genetic algorithms, human mate choice, evolutionary game theory and the origins of language, music, culture, intelligence, ideology and consciousness. His main research area is evolutionary psychology, and he is currently writing a trade book about the role of mate choice in human mental evolution.

Steven Mithen is Reader in Early Prehistory at the University of Reading. He studied at Sheffield, York and Cambridge Universities and has research interests in human evolution and early prehistory, with specific regard to cognition and the use of computer simulation. As an active field archaeologist he has conducted excavations on hunter-gatherer settlements in Western Scotland and is currently co-director of the Dana-GhuywerFaynan Early Prehistory Project involving the excavation of terminal Pleistocene settlements in southern Jordan.

Daniel Nettle received his $\mathrm{PhD}$ in Anthropology from University College London. He is currently a fellow of Merton College, Oxford, where he studies the evolution of linguistic and cultural diversity, both at a theoretical level and through field studies in West Africa.

Camilla Power has degrees in Mathematics from Oxford University and in Social Anthropology from London University, and is presently $\mathrm{PhD}$ candidate in the Department of Anthropology, University College London. She has authored a number of articles on sex, gender, cosmetics and the evolutionary origins of ritual.

Ian Watts was awarded his PhD in 1998. His doctoral research, carried out at the Department of Anthropology, University College London, is primarily concerned with the ochre record from the Upper Pleistocene Middle Stone Age of Southern Africa. 
